\title{
Psychometric properties of the Portuguese version of the Frost Multidimensional Perfectionism Scale
}

\author{
Propiedades Psicométricas de la Versión Portuguesa de la Escala de Perfeccionismo Multidimensional \\ de Frost
}

Marco Correia ${ }^{1 *}$, António Rosado¹, Sidónio Serpa ${ }^{1}$

\begin{abstract}
Perfectionism is defined as the desire to achieve the highest standards of performance, in combination with unduly critical evaluations of one's performance. This study was designed to analyse the psychometric proprieties of the Portuguese version of the Frost Multidimensional Perfectionism Scale through confirmatory factor analysis in two different samples (calibration with 350 adolescent athletes and validation with 206 adolescent athletes). The confirmatory factor analysis suggested that after dropping items with low factor loadings, the six-factor model showed good fit $\left(\chi^{2}=292.83\right.$, B-S $p<0.001 ; \chi^{2} / d f=1.693$, PCFI $=0.79$, PGFI $=0.70, \mathrm{CFI}=0.96$, GFI $=0.93$, RMSEA $=0.045)$. All constructs presented good internal consistency, convergent and discriminant validity. A multi-group analysis exposed the cross validity of the model. The correlations between perfectionism, fear of failure and sport anxiety measures revealed evidence of its concurrent validity, providing evidence for the proposed model. Overall, the results of the present study provided evidence for these instruments' validity and reliability, however further investigations are required.

Resumen

El perfeccionismo se define como el deseo de alcanzar altos modelos de rentabilidad asociado a evaluaciones críticas relativas a su rentabilidad. Este estudio tuvo por objetivo realizar un análisis psicométrico de la versión Portuguesa de la Escala Multidimensional de Perfeccionismo de Frost, en dos muestras diferentes (calibración con 350 atletas adolescentes y validación con 206 atletas adolescentes). El análisis factorial confirmatorio sugierió que después de dejar caer artículos con cargas bajas de factores, el modelo de seis factores mostró un buen ajuste $\left(\chi^{2}=292.83\right.$, B-S $p<0.001 ; \chi^{2} / d f=1.693, \mathrm{PCFI}=0.79, \mathrm{PGFI}=0.70, \mathrm{CFI}=0.96, \mathrm{GFI}=0.93$, RMSEA $=0.045$ ). Las propiedades psicométricas del nuevo modelo han demostrado una buena consistencia interna, validad convergente y discriminante. El análisis multigrupos realizado ha comprobado la validad cruzada del modelo. Las correlaciones entre el perfeccionismo, el miedo a fallar y la ansiedad deportiva han revelado su validéz concurrente, proveyendo así evidencias de que el modelo propuesto es una herramienta válida para acceder al perfeccionismo en el contexto deportivo Portugués, sin embargo futuras investigaciones son necesarias.
\end{abstract}

\section{Keywords}

athletes; factorial structure; perfectionism; sports; validation

Palabras Clave

atletas; deportes; estructura factorial; perfeccionismo; validación

${ }^{1}$ Faculty of Human Kinetics, University of Lisbon, Portugal

*Corresponding author: marc.correia@gmail.com

Manuscript received 09-03-2016; revised 08-06-2016; accepted 22-12-2016.

\section{Introduction}

Perfectionism has been defined as the setting of excessively high standards of performance in conjunction with a tendency to make overly critical self-evaluations (Frost, Marten, Lahart,
\& Rosenblate, 1990). This perspective, derived from a review of the existing literature on perfectionism, allowed the identification of several dimensions of perfectionism and included: (a) personal standards (PS; conceptualized as the setting of very high standards and the excessive importance placed on 
these high standards for self-evaluation); (b) concern over mistakes (COM; conceptualized as negative reactions to mistakes, a tendency to interpret mistakes as equivalent to failure, and a tendency to believe that one will lose the respect of others following failure); (c) parental expectations (PE; conceptualized as the tendency to believe that one's parents set very high goals and are overly critical); (d) doubts about actions (DAA; conceptualized as the tendency to feel that projects are not completed to satisfaction); (e) parental criticism (PC; conceptualized as the perception that one's parents are, or were, overly critical); and (f) organization (O; conceptualized as the overemphasis on precision, order and organization). To assess these various dimensions of perfectionism Frost et al. (1990) developed the Frost Multidimensional Perfectionism scale (Frost-MPS: Frost et al. (1990). Several authors validated this instrument in different populations (Ablard \& Parker, 1997; Parker \& Adkins, 1995; Parker \& Stumpf, 1995) and support was found in this structure using confirmatory factor analysis Parker and Adkins (1995); Parker and Stumpf (1995).

A similar self-reported measure of perfectionism was designed by P. L. Hewitt and Flett (1991) The Hewitt Multidimensional Perfectionism Scale (Hewitt-MPS: P. L. Hewitt \& Flett, 1991). This scale contains three subscales labelled self-oriented perfectionism (SOP), socially prescribed perfectionism (SPP), and other-oriented perfectionism (OOP). Theoretically, meaningful relationships have been observed between the subscales of the two instruments. For example, strong positive correlations $(r s>0.60)$ are generally observed between the PS subscale of the Frost-MPS and the SOP subscale of the Hewitt-MPS (see Cox, Enns, \& Clara, 2002). Moderate to strong positive correlations ( $r s>0.47)$ are also generally obtained between the PE, PC, and COM subscales of the Frost-MPS and the SPP subscale of the Hewitt-MPS.

Consistent patterns of correlations highlighting the functional nature of the Frost-MPS and Hewitt-MPS susbcales in sport domain are also evident in the literature. Research has shown that the COM, PE, PC, and DAA subscales of the Frost-MPS are generally associated with maladaptive correlates of perfectionism including heightened anxiety Hall, Kerr, and Matthews (1998), fear of failure Conroy, Kaye, and Fifer (2007) increased burnout Gould, Tuffey, Udry, and Loehr (1996), lowered self-esteem Gotwals, Dunn, and Wayment (2003), and increased pressure to overcome mistakes (Frost \& Henderson, 1991).

Conroy, Willow, and Metzler (2002) investigated how aspects of perfectionism in athletes relate to the fears of failure. Findings suggested that the perfectionist concerns dimension of perfectionism displays close links to fears of failure. Similar positive correlations between perfectionism concerns over mistakes with all five fears of failure were identified in Kaye, Conroy, and Fifer (2008) study. Conroy et al. (2002) investigated how aspects of perfectionism in athletes relate to the fears of failure. Findings suggested that the perfectionist concerns dimension of perfectionism displays close links to fears of failure. Similar positive correlations between perfectionism concerns over mistakes with all five fears of failure were identified in Kaye et al. (2008) study. Sagar and Stoeber (2009) showed that concern over mistakes predicted higher levels of all fears of failure.

According to Hall et al. (1998), the perfectionism motivational construct may have a significant impact upon the cognitive appraisal process and predispose athletes to experience achievement anxiety. These authors concluded that overall perfectionism underpins achievement anxiety as it emerged as a consistent predictor of cognitive anxiety prior to performance. Kawamura, Hunt, Frost, and DiBartolo (2001) demonstrated that increased concern over mistakes and doubts about action were associated with higher levels of anxiety symptoms.

Similar findings were reported on an investigation into running addiction by Coen and Ogles (1993), arguing that athletes who had a tendency to express doubts about the quality of their performances reported significantly higher trait anxiety. In the same way, Martinent, Campo, and Ferrand (2012), confirmed previous results regarding strong associations between perfectionism subscales and specific dimensions of state anxiety.

In sum, these findings suggest that perfectionism may promote the use of maladaptive motivational cognitions during the performance process, which will possibly threaten the athlete's self-worth and eventually might contribute to the prediction of multidimensional state anxiety in sport.

The Frost-MPS has been translated into German (AltstötterGleich \& Bergemann, 2006), French (Rhéaume, Freeston, Dugas, Letarte, \& Ladouceur, 1995), Chinese (Cheng, Chong, \& Wong, 1999), Spanish (Gelabert et al., 2011), showing good psychometric properties.

Some perfectionism theorists (e.g. Missildine, 1963; Shafran, Cooper, \& Fairburn, 2002) proposed that perfectionist tendencies may only function in specific areas of people's lives. Due to this point of view, some sport-specific domain perfectionism measures, started to be developed, validated and adapted to other languages and cultures such as Portuguese (Anshel \& Eom, 2003; Dunn, Causgrove Dunn, \& Syrotuik, 2002; Gotwals \& Dunn, 2009; Junior, Vissoci, Lavallee, \& Vieira, 2015; Soares, Gomes, Macedo, \& Azevedo, 2003). On the other hand, and according to Hewitt, P. Hewitt, Flett, Besser, Sherry, and McGee (2003): "it has been demonstrated empirically that individuals with a high level of commitment to one perfectionistic goal also tend to have elevated levels of commitment to a wide range of other perfectionistic goals and that the greater the importance placed on being perfect in many domains, the greater the depressive symptomatology in perfectionists". This is the main reason why there are still a great amount of uses of the original Frost-MPS in several domains and languages.

To date, and to our knowledge, the Frost-MPS has been adapted to Portuguese sport context by Serpa, Alves, and Barreiros (2004) with questionable reliability results in almost all subscales (concern over mistakes $=.78$; doubts about 
actions $=52 ;$ parental expectations $=.68 ;$ parental criticism $=.66$; personal standars $=.68$; organization $=83$ ).

Therefore, it was our intention to analyse the psychometric proprieties of the Frost Multidimensional Perfectionism scale in its Portuguese version in the universe of Portuguese athletes, in order to provide a psychometrically valid and reliable instrument. More specifically, we intended to use the data collected to analyse the six-factor structure as it was proposed by the Frost-MPS authors. Furthermore, into a more refined analysis, we tested the model to determine its internal consistency and convergent validity; tested the invariance of the structure with a cross-validation strategy; and explored the concurrent validity with a sample of Portuguese athletes.

\section{Method}

\subsection{Participants}

The study encompassed a total of 556 adolescent athletes in two convenience samples, with an age range from 12 to 18 years old. The first sample (calibration), used for confirmatory factor analysis purposes, with 350 athletes (94 female, 256 male) had a mean age of 15.65 years old $(S D=2.45)$, while the second sample (validation), used for cross-validity purposes, had 206 athletes with a mean age of 15.29 years old $(S D=2.47)$.

\subsection{Procedures}

The study was reviewed by the University Ethics Board prior to data collection. Letters and parental consent forms were sent home to parents for participants under the age of 18 informing them of the nature of the study and requesting their permission for their child's participation in the study. All participants, including minors, signed consent forms.

\subsection{Mesures}

The Portuguese version of the Frost et al. (1990) Multidimensional Perfectionism scale (MPS-F) was translated and adapted by Serpa et al. (2004). This 35-item questionnaire generates an overall perfectionism score as well as scores for six subscales that reflect specific domains of perfectionism: (1) concern over mistakes, (2) doubts about actions, (3) personal standards, (4) parental expectations, (5) parental criticism, and (6) organization. The total perfectionism score is the sum of all subscales except organization Frost et al. (1990).

The Portuguese version of the Performance Failure Appraisal Inventory PFAI (Conroy et al., 2002), translated and adapted and validated by Correia, Rosado, and Serpa (2016) is a multidimensional measure of threat appraisals associated with fear of failure. Participants were asked to rate how strongly they believed each of the 14 aversive consequences of failure were likely to occur to them after failing. Items were answered on a five-point Likert scale from 1 (do not believe at all) to 5 (truly believe). The Portuguese version of the Performance Failure Appraisal Inventory $\left(P F A I_{p}\right)$ subscale scores was derived by summing scores on the individual items for each subscale. A composite fear of failure score can be derived by summing all 14 items.

The Portuguese version of the Sport Anxiety Scale SAS-2 Smith, Smoll, Cumming, and Grossbard (2006) translated and adapted by Cruz and Gomes (2007) has tree subscales (somatic anxiety, worry, and concentration disruption) each consist of five items. Satisfactory psychometric proprieties of this instrument were obtained in Dias, Cruz, and Fonseca (2009) study. A composite anxiety score can be derived by summing all 15 items.

\subsection{Data Analysis}

Data analysis, were performed using AMOS 22.0 (SPSS Inc. Chicago IL) and a confirmatory factor analysis (CFA) was performed to assess the psychometric proprieties of the FrostMPS instrument. The maximum likelihood (ML) method was used. Following discovery of unsatisfactory fit, modification indices and standardized estimates were examined to evaluate for alternative models or probable item removals.

A two-step confirmatory strategy was used (Anderson \& Gerbing, 1988; Byrne, 2010; Kline, 2011; Schumaker \& Lomax, 1996).

Univariate skewness and kurtosis of items were examined, as well as multivariate normal distribution using Mardia's (1970) coefficient of multivariate kurtosis West, Finch, and Curran (1995).

Internal consistency (reliability) of the constructs was assessed through composite reliability, and we followed the recommendations of Fornel and Larcker (1981) to calculate composite reliability (CR), in which it is recommended that values $\geq .7$ indicates a proper value of $\mathrm{CR}$.

In order to examine convergent validity, average variance extracted (AVE) values were considered, whereby values of $\mathrm{AVE} \geq .5$ are appropriate indicators of convergent validity Hair, Anderson, Tatham, and Black (2009).

Discriminant validity was established when AVE for each construct exceeded the squared correlations between that construct and any other Hair et al. (2009). In order to identify Frost-MPS' factorial invariance, cross validation procedures were used with a multi-group analysis strategy (Brown, 2006; Davey, 2010; Schumaker \& Lomax, 2004).

Assessment of model fit was based on multiple indicators (Hu \& Bentler, 1999; Marsh, 2007), namely: chi-square $\left(\chi^{2}\right)$ statistical test, the ratio of qui-square to its degrees of freedom $\chi^{2} / d f$, comparative-of-fit-index (CFI), goodness-of-fit index (GFI), parsimony comparative-of-fit-index (PCFI), parsimony goodness-of-fit index (PGFI), and root mean square error of approximation (RMSEA). Research practices using these indices state values for the $\chi^{2} / d f$ should be less than 3 , PCFI and PGFI above .60, while values above .95 for the CFI and GFI, and below .06 for the RMSEA represent a good fit (Arbuckle, 2009; P. M. Bentler \& Bonett, 1980; Blunch, 2008; Kline, 2011).

To study the adequacy of model replication a multigroup analysis was conducted with the calibration sample $(n=$ 
$350)$ and the second sample, as validation sample $(n=206)$. Model's invariance was tested by comparing the unconstrained model with constrained models (factor loadings fixed and variances/co-variances fixed). Factorial invariance was accepted when the models did not differ significantly $(p>.05)$, according to the chi-square statistic (Loehlin, 2003; Marôco, 2010). We also considered Cheung and Rensvold (2002) suggestion that a difference of CFI of less than or equal to .01 is an indication that the constrained parameters are invariant.

Concurrent validity was analysed by Pearson's correlation coefficients between the MPS-F's, the SAS-2 and PFAI's dimensions as well as their total score values. Evidence of the concurrent validity was obtained by studying the association among constructs measures that, theoretically, should be related, confirming, empirically, these relationships between the constructs Campbell and Fiske (1959).

\section{Results}

\subsection{Preliminary analysis}

On the data there were no missing values and it was approximately univariately normal, since items with absolute values of skewness lower than 3 and kurtosis lower than 7 did not deviate enough from the normal distribution Kline (2004).

Results of Mardia (1970) coefficient revealed that data violated the assumption of a multivariate Gaussian distribution P. M. Bentler and $\mathrm{Wu}$ (1993), and a bootstrapping procedure of Bollen and Stine (1993) was applied to adjust the $p$ value of the chi-square statistic.

\subsection{Evaluation of Model Fit}

Formerly, not all estimated factor loadings exceed the cut-off point of .50 (see Table 1), and according to Hair et al. (2009) "standardized loading estimates should be .50 or higher, and ideally .70 or higher" (p. 679). The goodness-of-fit indices produced for this first order measurement model indicated an unsatisfactory fit $\left(\chi^{2}=1450.899\right.$, B-S $p<0.01$; $\chi^{2} / d f=2.83$, PCFI $=.74$, PGFI $=.68, \mathrm{CFI}=.81$, RMSEA $=.072[\mathrm{CI}=.067-.076])$ showing that the hypothesized measurement model is inconsistent with observed data, and it is interpreted as evidence against the adequacy of the model.

Due to the lack of support from CFA performed, post hoc model adjustments were conducted in an effort to develop a better fitting model and further analyses became exploratory in the sense that they focused on the detection of misfitting parameters in the originally hypothesized model Byrne (2010).

Since the results in the original model (first-order model) indicated that not all items did load significantly on its construct, in the interest of scientific parsimony, all scale items that showed unacceptable factor loadings were removed Byrne (2010). This process resulted in the removal of item 10 and 16, from the original model. Examination of the modification indices (MI), suggested that an improved model resulted in the elimination of the items 4, 14, 15, 17, 18, 24, 26 and 29, following the intent of Chartrand, Robbins, Morril, and Boggs (1990) to create "pure measures of each factor" (p. 495) by allowing items to load on only one factor. We tried to keep the number of items eliminated from the model as small as possible and to leave at least three per factor, in accordance with the recommendations of Hatcher (1994). According to Byrne (2010) large MI argue the presence of factor-cross loadings (i.e., a loading on more than one factor) and error covariances, respectively. The measures errors covariances observed could represent a systematic, rather than random measurement in item responses, and they may derive from characteristics specific either to the items or to the respondents Aish and Jöreskog (1990). Another type of method effect that can trigger error covariance is a high degree of overlap in item content. This redundancy occurs when an item, although worded differently, essentially asks the same question or is related to another factor Byrne (2010). A large error covariance between items 7 and 31 remained present $(\mathrm{MI}=47.81$, $\mathrm{EPC}=0.25)$. This suggested that allowing the two errors to correlate would significantly improve model fit. Examining items 7 ("I am a neat person") and 31 ("I am an organized person"), it was clear that they were attempting to measure perfectionism related to Organization. Given the redundancy between both items we decided to correlate the two errors involved.

At this point of model adjustments, and besides the acceptable fit indices showed, the model was presenting some validity concerns (e.g., discriminant and convergent validity), specifically on the Concern Over Mistakes, Doubts About Actions and Parental Criticism factors. In order to insure reliability and model parsimony we eliminated item 13 , item 28 , and item 34 who showed to be the lowest factorial weight on their constructs (Biscaia, Correia, Rosado, Maroco, \& Ross, 2012; Gladden \& Funk, 2002).

As reported in Table 2, standardized items loadings and the z-values provided evidence that the items accurately captured their respective factorsAnderson and Gerbing (1988).

After these procedures, the model adjusted to the data, since the results obtained demonstrated an acceptable fit $\left[\chi^{2}=\right.$ 292.83, B-S $p<0.001 ; \chi^{2} / d f=1.693$, PCFI $=0.70$, CFI $=0.96, \mathrm{RMSEA}=0.045(\mathrm{CI}=.036-.054)]$. All composite reliability values exceeded the recommended minimum .70 for psychological scales Fornell and Larcker (1981) and the AVE values provided evidence of convergent validity, as reported in Table 3.

Furthermore, all constructs were considered to exhibit discriminant validity because all AVE values exceeded the appropriate square factor correlations. Overall, the measurement model was within the required criteria and showed good psychometric proprieties.

The second-order measurement model (Figure 1) showed an overall acceptable fit to the data $\left(\chi^{2}=387.559\right.$, B-S $p<$ $0.01 ; \chi^{2} / d f=2.129, \mathrm{PCFI}=0.80, \mathrm{PCFI}=0.71, \mathrm{CFI}=0.93$, RMSEA $=0.058[C I=.050-.066])$. 
Table 1

Factor Loadings, Z-values, Composite Reliability (CR), and Average Variance Extracted (AVE) for the sub-dimensions of the MPS-F model.

\begin{tabular}{|c|c|c|c|c|}
\hline MPS-F Factors/Items & Loadings & Z-value & $\alpha / \mathbf{C R}$ & AVE \\
\hline Concern Over Mistakes & & & .85 & .40 \\
\hline 34 - The fewer mistakes I make, the more people will like me. & .561 & 10.816 & & \\
\hline 25 - If I do not do well all the time, people will not respect me. & .719 & 14.835 & & \\
\hline $\begin{array}{l}23 \text { - If I do not do as well as other people, it means I am an inferior human } \\
\text { being. }\end{array}$ & .669 & 13.454 & & \\
\hline 21 - People will probably think less of me if I make a mistake. & .653 & 13.033 & & \\
\hline 18 - I hate being less than the best at things. & .656 & 13.134 & & \\
\hline 14 - If I fail partly, it is as bad as being a complete failure. & .655 & 13.098 & & \\
\hline $\begin{array}{l}13 \text { - If someone does a task at work/school better than I do, then I feel like I } \\
\text { failed }\end{array}$ & & & & \\
\hline the whole task. & .643 & 12.797 & & \\
\hline 10 - I should be upset if I make a mistake. & .479 & 8.992 & & \\
\hline 9 - If I fail at work/school, I am a failure as a person. & .591 & 11.504 & & \\
\hline Doubts About Actions & & & .65 & .31 \\
\hline 33 - It takes me a long time to do something "right". & .534 & 8.963 & & \\
\hline 32 - I tend to get behind in my work because I repeat things over and over. & .583 & 9.853 & & \\
\hline 28 - I usually have doubts about the simple everyday things I do. & .606 & 10.279 & & \\
\hline $\begin{array}{l}17 \text { - Even when I do something very carefully, I often feel that it is not quite } \\
\text { right. }\end{array}$ & .512 & 8.552 & & \\
\hline Parental Expectations & & & .79 & .43 \\
\hline $\begin{array}{l}26 \text { - My parents have always had higher expectations for my future than I } \\
\text { have. }\end{array}$ & .526 & 9.768 & & \\
\hline 20 - My parents have expected excellence from me. & .740 & 14.970 & & \\
\hline 15 - Only outstanding performance is good enough in my family. & 699 & 13.880 & & \\
\hline 11 - My parents wanted me to be the best at everything. & .708 & 14.116 & & \\
\hline 1 - My parents set very high standards for me. & .583 & 11.054 & & \\
\hline Parental Criticism & & & .76 & .44 \\
\hline 35 - I never felt like I could meet my parents' standarts. & .760 & 15.114 & & \\
\hline 22 - I never felt like I could meet my parents' expectations. & .740 & 14.626 & & \\
\hline 5 - My parents never tried to understand my mistakes. & .559 & 10.337 & & \\
\hline 3 - As a child, I was punished for doing things less than perfect. & .570 & 10.565 & & \\
\hline Personal Standards & & & .83 & .42 \\
\hline 24 - Other people seem to accept lower standards from themselves than I do. & .625 & 12.193 & & \\
\hline 6 - It is important to me that I be thoroughly competent in everything I do. & .690 & 13.867 & & \\
\hline 16 - I am very good at focusing my efforts on attaining a goal. & .420 & 7.681 & & \\
\hline 30 - I expect higher performance in my daily tasks than most people. & .735 & 15.107 & & \\
\hline 19 - I have extremely high goals. & .681 & 13.626 & & \\
\hline 12 - I set higher goals than most people. & .722 & 14.725 & & \\
\hline $\begin{array}{l}4 \text { - If I do not set the highest standards for myself, I am likely to end up a } \\
\text { second-rate person. }\end{array}$ & .579 & 11.117 & & \\
\hline Organization & & & .86 & .51 \\
\hline 31- I am an organized person. & .743 & 15.423 & & \\
\hline 29 - Nearness is very important to me. & .510 & 9.613 & & \\
\hline 27 - I try to be a neat person. & .790 & 16.813 & & \\
\hline 8 - I try to be an organized person. & .763 & 16.010 & & \\
\hline 7 - I am a neat person. & .776 & 16.404 & & \\
\hline 2 - Organization is very important for me. & .668 & 13.379 & & \\
\hline
\end{tabular}

Note. Factor Loadings $<.50$ items are in boldface. 


\section{Table 2}

MPS-F Re-specified 1st Order Model - Factor loadings, Zvalues, composite reliability $(C R)$ and average variance extracted (AVE).

\begin{tabular}{lcccc}
\hline MPS-F Factors/Items & Loadings & Z-value & $\alpha /$ CR & AVE \\
\hline Concern Over Mistakes & & & 0.80 & 0.50 \\
Item 25 & .799 & 16.119 & & \\
Item 23 & .734 & 14.408 & & \\
Item 21 & .690 & 13.304 & & \\
Item 9 & .600 & 11.175 & & \\
Doubts About Actions & & & 0.70 & 0.50 \\
Item 33 & .806 & 8.646 & & \\
Item 32 & .569 & 7.459 & & \\
Parental Expectations & & & 0.75 & 0.51 \\
Item 20 & .736 & 13.945 & & \\
Item 11 & .778 & 14.902 & & \\
Item 1 & .614 & 11.216 & & \\
Parental Criticism & & & 0.74 & 0.50 \\
Item 35 & .775 & 14.847 & & \\
Item 22 & .793 & 15.246 & & \\
Item 5 & .506 & 8.984 & & \\
Personal Standards & & & 0.83 & 0.50 \\
Item 6 & .714 & 13.970 & & \\
Item 30 & .753 & 14.989 & & \\
Item 19 & .727 & 14.314 & & \\
Item 12 & .736 & 14.538 & & \\
Organization & .853 & & 0.87 & 0.57 \\
Item 31 & .698 & 13.873 & & \\
Item 27 & .863 & 18,763 & & \\
Item 8 & .820 & 17.437 & & \\
Item 7 & .650 & 14.897 & & \\
Item 2 & & & & \\
\hline
\end{tabular}

Table 3

Discriminant validity for MPS-F's Re-specified 1st Order Model

\begin{tabular}{cccccccc}
\hline & & CM & DA & PE & PC & PS & O \\
\hline & AVE & 0.50 & 0.50 & 0.51 & 0.50 & 0.50 & 0.57 \\
CM & 0.50 & 1 & & & & & \\
DA & 0.50 & 0.09 & 1.00 & & & & \\
PE & 0.51 & 0.31 & 0.02 & 1.00 & & & \\
PC & 0.50 & 0.30 & 0.19 & 0.33 & 1.00 & & \\
PS & 0.50 & 0.20 & 0.00 & 0.22 & 0.01 & 1.00 & \\
O & 0.57 & 0.01 & 0.00 & 0.00 & 0.01 & 0.16 & 1 \\
\hline
\end{tabular}

Note. $\mathrm{CM}=$ concern over mistakes; DA = doubts about actions; $\mathrm{PE}=$ parental expectations; $\mathrm{PC}=$ parental criticism; $\mathrm{PS}=$ personal standards; $\mathrm{O}=$ organization; $\mathrm{AVE}=$ average variance extracted.

\subsection{Cross-validity}

The fit of the unconstrained model (Model A: $\chi^{2}[346]=$ 464.72, B-S $p<.001, \mathrm{PCFI}=0.79, \mathrm{PGFI}=0.67, \mathrm{CFI}=$ 0.96 , GFI $=0.89$, RMSEA $=0.032)$ was acceptable. The models with constrained factor loadings (Model B: $\chi^{2}$ [367] $=490.57, \mathrm{~B}-\mathrm{S} p<.001, \mathrm{PCFI}=0.83, \mathrm{PGFI}=0.70, \mathrm{CFI}$ $=0.96, \mathrm{GFI}=0.89, \mathrm{RMSEA}=0.032)$, and with constrained
Figure 1. Respecified second-order model of the Frost Multidimensional Perfectionism scale

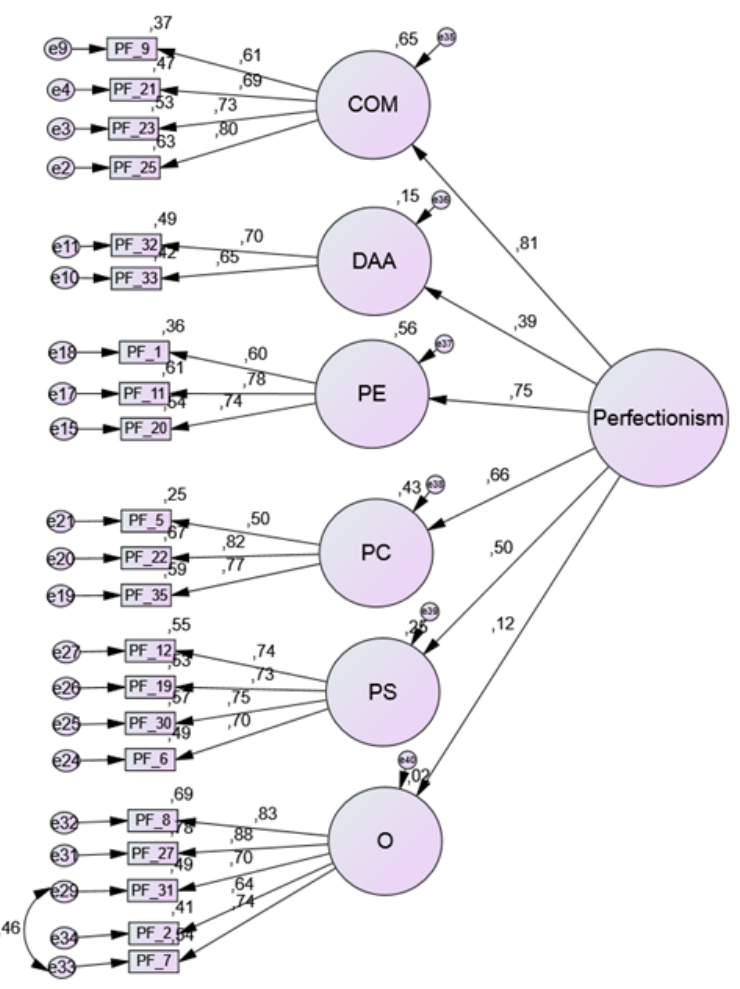

variances/covariances (Model C: $\chi^{2}[382]=512.15$, B-S $p<.001, \mathrm{PCFI}=0.87, \mathrm{PGFI}=0.73, \mathrm{CFI}=0.95, \mathrm{GFI}$ $=0.88$, RMSEA $=0.032$ ), showed a satisfactory fit. The $\chi^{2}$ statistic difference showed no significant dissimilarities between Model A and Model B ( $\chi^{2}$ dif [21] $\left.=25.9 ; p=.109\right)$, and also no significant differences between Model $\mathrm{A}$ and Model C $\left(\chi^{2}\right.$ dif [36] $\left.=47.43 ; p=.214\right)$. Moreover, since there were no significant differences in the CFI values for all model comparisons, the results demonstrated the model's invariance in both samples, indicating that the factorial structure of the scale was stable in the two independent samples Cheung and Rensvold (2002).

\subsection{Concurrent Validity}

The results presented in Table 4, using the validation sample, revealed that all dimensions of perfectionism and SAS-2 subscales and total scores were positively correlated, except for somatic anxiety factor and organization factor. All aspects of perfectionism showed positive correlations with the different fears of failure dimensions, except for organization factor. Perfectionism total scores were also positively correlated with fear of failure total score.

\section{Discussion}

The purpose of this study was to test the factorial validity in a Portuguese sport setting of the Frost Multidimensional Per- 
Psychometric properties of the Frost-MPS (Research Article) - 14/17

Table 4

Correlation matrix between Frost Multidimensional Perfectionism Scale (MPS-F), Sport Anxiety Scale-2 (SAS-2) and Performance Failure Appraisal Inventory (PFAI)

\begin{tabular}{lccccccc}
\hline & CM & DA & PE & PC & PS & O & P-TS \\
SAS - Somatic Anxiety & $.215^{* *}$ & $.222^{* *}$ & $.118^{* *}$ & $.185^{* *}$ & .102 & -.050 & $.207^{* *}$ \\
SAS - Worry & $.331^{* *}$ & $.166^{* *}$ & $.218^{* *}$ & $.157^{* *}$ & $.318^{* *}$ & $.108^{*}$ & $.312^{* *}$ \\
SAS - Concentration Disruption & $.211^{* *}$ & $.252^{* *}$ & $.136^{*}$ & $.188^{* *}$ & .036 & $-.141^{* *}$ & $.203^{* *}$ \\
SAS - Total Score & $.260^{* *}$ & $.253^{* *}$ & $.156^{* *}$ & $.206^{* *}$ & $.124^{*}$ & -.066 & $.249^{* *}$ \\
FSE & $.466^{* *}$ & $.284^{* *}$ & $.339^{* *}$ & $.296^{* *}$ & $.333^{* *}$ & .067 & $.454^{* *}$ \\
FDSE & $.469^{* *}$ & $.320^{* *}$ & $.292^{* *}$ & $.390^{* *}$ & $.244^{* *}$ & -.007 & $.452^{* *}$ \\
FUF & $.503^{* *}$ & $.260^{* *}$ & $.310^{* *}$ & $.302^{* *}$ & $.332^{* *}$ & .032 & $.459^{* *}$ \\
FIOLI & $.531^{* *}$ & $.228^{* *}$ & $.410^{* *}$ & $.332^{* *}$ & $.386^{* *}$ & .023 & $.502^{* *}$ \\
FUIO & $.389^{* *}$ & $.196^{* *}$ & $.349^{* *}$ & $.224^{* *}$ & $.280^{* *}$ & .068 & $.392^{* *}$ \\
FF-TS & $.549^{* *}$ & $.295^{* *}$ & $.390^{* *}$ & $.354^{* *}$ & $.344^{* *}$ & .042 & $.523^{* *}$ \\
\hline
\end{tabular}

Note. FSE = fear of experiencing shame \& embarrassment; FDSE = fear of devaluing one's self-estimate; FUF = fear of having an uncertain future; FIOLI = fear of important others losing interest; FUIO = fear of upsetting important others; FF-TS = fear of failure total score; $\mathrm{CM}=$ concern over mistakes; $\mathrm{DA}=$ doubts about actions; $\mathrm{PE}=$ parental expectations $; \mathrm{PC}=$ parental criticism; $\mathrm{PS}=$ personal standards; $\mathrm{O}=$ organization; $\mathrm{P}-\mathrm{TS}=$ perfectionism total score. $* \mathrm{~B}-\mathrm{S} p<.05 ; * * \mathrm{~B}-\mathrm{S} p<.01$.

fectionism scale (Frost-MPS), originally developed by Frost et al. (1990).

The confirmatory factorial analysis performed on the FrostMPS, to a sample of 556 athletes, presented lack of support from CFA performed. Even though the original factor structure of the scale was confirmed in our study, several problems were detected, namely items with unacceptable factor loadings in their different subscales, reliability issues and convergent validity problems. The lack of strong statistical support for the original model led us to a respecification and a reestimation of the model. Although confirmatory factor analysis continued to be used, it should be clearly acknowledged that these analyses are exploratory in the sense that they focus on the detection of misfitting parameters in the originally hypothesized model in order to investigate an alternative structure to better represent the sample of athletes.

The factor analysis using the re-specified model showed an acceptable fit for the Portuguese athletes' sample and confirmed a first-order construct and, as well as, a second-order construct. The first-order construct showed composite reliability, convergent validity and discriminant validity. However, in the re-specification process, doubts about actions' factor possesses only two items and it its recognised to be a problematic issue for some time.

The correlation coefficients between the six subscales of the Portuguese version of the Frost-FPM were somehow analogous to the ones obtained by Frost et al. (1990).Concern over mistakes presented the highest correlations with all the subscales. Instead, organization was not strongly associated with all the subscales, except for the personal standards subscale. According to Frost and Henderson (1991) organization and personal standards subscales reflect a positive feature of perfectionism and consequently presented a strong correlation. Furthermore, these two subscales capture the first component of perfectionism, namely the tendency to aspire to the highest standards of performance, without the explicit meaning of what violations of those standards might mean to the self Frost et al. (1990). On the other hand, and similar to Frost et al. (1990) study, organization was not strongly associated with any other subscales.

The model's invariance in the two independent samples was supported, indicating cross validity.

Frost-MPS's concurrent validity has been ascertained and, as expected, scores have exhibited appropriate convergent validity with measures of sport anxiety and fear of failure (Conroy et al., 2007; Frost \& Henderson, 1991; Kawamura et al., 2001; Sagar \& Stoeber, 2009), providing additional support for its construct validity. In previous studies, concern over mistakes dimension was strongly correlated with competitive anxiety (Frost \& Henderson, 1991; Hall et al., 1998; Kawamura et al., 2001). Likewise, a positive correlation was found in our study with all dimensions of sport anxiety, providing additional evidence for convergent validity.

Correlations between all dimensions of perfectionism and fear of failure reported medium to strong positive correlations and are similar to previous studies (Conroy et al., 2007; Kaye et al., 2008; Sagar \& Stoeber, 2009) providing, once more, the concurrent validity of the MPS-F $F_{p}$.

Regarding the re-specification done, it must be recognised that previous investigations of the factor structure have arrived at divergent solutions (i.e., several items did not load on their respective factor and the factor structure was not always replicated). Purdon, Antony, and Swinson (1999) found a three factor solution in a sample of anxiety disorders, and other researchers found four factor solutions (Harvey, Pallant, \& Harvey, 2004; Stumpf \& Parker, 2000) Further analysis must be done, with different factor solutions.

Finally, there are limitations that need to be acknowledged. 
Further research is necessary in order to further establish factorial validity and reliability, namely factorial invariance analysis and exploratory factor analysis. One limitation of this study has to do with the fact that our sample is different from the one that was used by the original authors. The sample of the original authors and most of the studies conducted to inspect the psychometric proprieties were composed by university students, whereas the Portuguese sample originated from adolescents' sports leagues and federations.

In our study, a post hoc model modification was used, refining the measurement instrument. This procedure helped to identify factorial ambiguous items that can be removed from the model Markland and Ingledew (1997). According to Hofmann (1995), this approach does not comprise the integrity of the a priori model, since the model remains essentially the same; it simply has fewer indicators of its factors. However, it should be unequivocally acknowledged that, since we adopted an exploratory model generation approach and by itself represents a departure from the hypothetic-deductive model testing ideal, which structural equation modelling was principally designed in the first place (P. Bentler \& Chou, 1987; Biddle, 1987), further replication with the resulting model must be done.

This study will promote additional research regarding the psychometric proprieties of one of the world's most widely used instrument to access perfectionism, that until now received scant attention in Portuguese sport context.

\section{References}

Ablard, K. E., \& Parker, W. D. (1997). Parents' achievement goals and perfectionism in their academically talented children. Journal of Youth and Adolescence, 26, 651668. doi: 10.1023/A:1022392524554

Aish, A. M., \& Jöreskog, K. G. (1990). A panel model for political efficacy and responsiveness: An aplication of lisrel 7 with weighted least squares. Quality and Quality, 24, 405-426.

Altstötter-Gleich, C., \& Bergemann, N. (2006). Testgüte einer deutschsprachigen version der mehrdimensionalen perfektionismus skala von frost, marten, lahart und rosenblate (mps-f). Diagnostica, 52(3), 105-118. doi: 10.1026/0012-1924.52.3.105

Anderson, J. C., \& Gerbing, D. W. (1988). Structural equation modeling in practice: A review and recommended twostep approach. Psychological Bulletin, 103(3), 411423.

Anshel, M. H., \& Eom, H. J. (2003). Exploring the dimensionality of perfectionism in sport. International Journal of Sport Psychology, 34(255-271).

Arbuckle, J. (2009). Amos18 reference guide (version 18). Chicago, IL: Statistical Package for the Social Sciences.

Bentler, P., \& Chou, C. P. (1987). Practical issues in structural modelling. Sociological Methods and Research, 16, 78-117. doi: 10.1177/0049124187016001004
Bentler, P. M., \& Bonett, D. G. (1980). Significance tests and goodness of fit in analysis of covariance structures. Psychological Bulletin, 88, 588-606. doi: 10.1037/ 0033-2909.88.3.588

Bentler, P. M., \& Wu, E. J. C. (1993). Eqs/windows user's guide. Los Angeles: BMDP Statistical Software.

Biddle, M. M., B.J.and Marlin. (1987). Causality, confirmation, credulity, and structural equation modeling. Child Development, 58(1), 4-17.

Biscaia, R., Correia, A., Rosado, A., Maroco, J., \& Ross, S. (2012). The effects of emotions on football spectators' satisfaction and behavioural intentions. European Sport Management Quarterly, 12(3), 227-242.

Blunch, N. J. (2008). Introduction to structural equation modeling using spss and amos. Thousand Oaks, CA: SAGE.

Bollen, K. A., \& Stine, R. A. (1993). Bootstrapping goodnessof-fit measures in structural equation models in bollen, k. long, j. In Testing structural equation models (p. 111135). Newbury Park, CA.

Brown, T. (2006). Confirmatory factor analysis for applied research. New York, NY: The Guildford Press.

Byrne, B. M. (2010). Structural equation modeling with amos: Basic concepts, applications, and programming. New York, NY.: Taylor and Francis Group.

Campbell, D., \& Fiske, D. (1959). Convergent and discriminant validation by the multitrait multimethod matrix. Psychological Bulletin, 56, 81-105. doi: 10.1037/ h0046016

Chartrand, J. M., Robbins, S. B., Morril, W. H., \& Boggs, K. (1990). Development and validation of the career factors inventory. Journal of Counseling Psychology, 37, 491-501. doi: 10.1037/0022-0167.37.4.491

Cheng, S. K. ., Chong, G. H., \& Wong, C. W. (1999). Chinese frost multidimensional perfectionism scale: A validation and prediction of self-esteem and psychological distress. Journal of Clinical Psychology, 55(9), 10511061.

Cheung, G., \& Rensvold, R. (2002). Evaluating goodness-offit indexes for testing measurement invariance. Structural Equation Modeling: A Multidisciplinary Journal, 9, 233-255. doi: 10.1207/S15328007SEM0902_5

Coen, S. P., \& Ogles, B. M. (1993). Psychological characteristics of the obligatory runner: a critical examination of the anorexia analogue hypothesis. Journal of Sport and Exercise Psychology, 15, 338-354.

Conroy, D. E., Kaye, M. P., \& Fifer, A. M. (2007). Cognitive links between fear of failure and perfectionism. Journal of Rational-Emotive and Cognitive Behavior Therapy, 25, 237-253. doi: 10.1007/s10942-007-0052-7

Conroy, D. E., Willow, J. P., \& Metzler, J. N. (2002). Multidimensional fear of failure measurement: The performance failure appraisal inventory. Journal of Applied Sport Psychology, 14, 74-90. doi: 10.1080/ 10413200252907752 
Correia, M., Rosado, A., \& Serpa, S. (2016). Fear of failure in sport: A portuguese cross-cultural adaptation. Motriz, 4(22), 376-382.

Cox, B. J., Enns, M. W., \& Clara, I. P. (2002). The multidimensional structure of perfectionism in clinically distressed and college student samples. Psychol Assess, 14(3), 365-373.

Cruz, J. F., \& Gomes, A. R. (2007). Escala de ansiedade no desporto (ead-2) - versão para investigação. Braga, Portugal: Universidade do Minho.

Davey, A. (2010). Statistical power analysis with missing data: A structural equation modeling approach. New York, NY: Taylor and Francis Group.

Dias, C., Cruz, J., \& Fonseca, A. (2009). Anxiety and coping strategies in sport contexts: A look at the psychometric properties of portuguese instruments for their assessment. The Spanish Journal of Psychology, 12(1), 338-348.

Dunn, J. G. H., Causgrove Dunn, J., \& Syrotuik, D. G. (2002). Relationship between multidimensional perfectionism and goal orientations in sport. Journal of Sport and Exercise Psychology, 24, 376-395.

Fornell, C., \& Larcker, D. (1981). Evaluation structural equations models with unobservable variable and measurement error. Journal of Marketing Research, 18, 39-50. doi: $10.2307 / 3151312$

Frost, R. O., \& Henderson, K. J. (1991). Perfectionism and reactions to athletic competition [Journal Article]. Journal of Sport and Exercise Psychology, 13, 323-335.

Frost, R. O., Marten, P., Lahart, C., \& Rosenblate, R. (1990). The dimensions of perfectionism. Cognitive Therapy and Research, 14, 449-468.

Gelabert, E., García-Esteve, L., Martín-Santos, R., Gutiérrez, F., Torres, A., \& Subira, S. (2011). Psychometric properties of the spanish version of the frost multidimensional perfectionism scale in women. Psicothema, 23, 133-139.

Gladden, J., \& Funk, D. (2002). Developing an understanding of brand associations in team sport: Empirical evidences from consumers of professional sport. Journal of Sport Management, 16, 54-81.

Gotwals, J. K., \& Dunn, J. G. H. (2009). A multi-method multi-analytic approach to establishing internal construct validity evidence: The sport multidimensional perfectionism scale 2. Measurement in Physical Education and Exercise Science, 13, 71-92.

Gotwals, J. K., Dunn, J. G. H., \& Wayment, H. A. (2003). An examination of perfectionism and self-esteem in intercollegiate athletes. Journal of Sport Behavior, 26(1), 17-38.

Gould, D., Tuffey, S., Udry, E., \& Loehr, J. (1996). Burnout in competitive junior tennis players: I. a quantitative psychological assessment. The Sport Psychologist, 10(4). doi: 10.1123/tsp.10.4.322

Hair, J., Anderson, R., Tatham, R., \& Black, W. (2009).
Multivariate data analysis. Upper Saddle River, NJ: Prentice Hall.

Hall, H. K., Kerr, A. W., \& Matthews, J. (1998). Precompetitive anxiety in sport: The contribution of achievement goals and perfectionism. Journal of Sport and Exercise Psychology, 20, 194-217.

Harvey, B., Pallant, J., \& Harvey, D. (2004). An evaluation of the factor structure of the frost multidimensional perfectionism scale. Educational Psychology Measure, 66(6), 1007-1018.

Hatcher, L. (1994). A step-by-step approach to using the sas ${ }^{\circledR}$ system for factor analysis and structural equation modeling. Cary, NC: SAS Institute Inc.

Hewitt, P., Flett, G., Besser, A., Sherry, S., \& McGee, B. (2003). Perfectionism is multidimensional: a reply to shafran, cooper and fairburn. Behaviour research and therapyl, 41(20), 1221-36.

Hewitt, P. L., \& Flett, G. L. (1991). Perfectionism in the self and social contexts: Conceptualization, assessment and association with psychopathology. Journal of Personality and Social Psychology, 60(3), 456-470.

Hofmann, R. (1995). Establishing factor validity using variable reduction in confirmatory factor analysis. Educational and Psychological Measurement, 55, 572-582.

Hu, L., \& Bentler, P. M. (1999). Cutoff criteria for fit indexes in covariance structure analysis: Conventional criteria versus new alternatives. Structural Equation Modelling: A Multidisciplinary Journal, 6, 1-55.

Junior, J., Vissoci, J., Lavallee, D., \& Vieira, L. (2015). Adaptation and validation of the sport multidimensional perfectionism scale-2 (smps-2) for the brazilian sport context. Motriz, 21(2), 125-136.

Kawamura, K. Y., Hunt, S. L., Frost, R. O., \& DiBartolo, P. M. (2001). Perfectionism, anxiety and depression: are the relationships independent? Cognitive Therapy and Research, 25, 291-301.

Kaye, M. P., Conroy, D. E., \& Fifer, A. M. (2008). Individual differences in incompetence avoidance. Journal of Sport and Exercise Psychology, 30, 110-132.

Kline, R. B. (2004). Beyond significance testing: Reforming data analysis methods in behavioral research. Washington, DC: American Psychological Association.

Kline, R. B. (2011). Principles and practices of structural equation modeling. New York, NY: The Guilford Press.

Loehlin, J. C. (2003). Latent variable models: An introduction to factor, path, and structural equation analysis. Mahwah, NJ: Lawrence Erlbaum Associates.

Mardia, K. V. (1970). Measures of multivariate skewness and kurtosis with applications. Biometrika, 57, 519-530.

Markland, D., \& Ingledew, D. K. (1997). The measurement of exercise motives: factorial validity and invariance across gender of a revised exercise motivations inventory. British Journal of Health Psychology, 2, 361-376.

Marôco, J. (2010). Análise de equações estruturais: fun- 
damentos teóricos, software and aplicações. Lisboa, Portugal: Report Number.

Marsh, H. W. (2007). Application of confirmatory factor analysis and structural equation modeling in sport/exercise psychology. In I. G. T. . R. C. Eklund (Ed.), Handbook of sport psychology (pp. 3rd ed., pp. 774-798). New York, NY: Wiley.

Martinent, G., Campo, M., \& Ferrand, C. (2012). A descriptive study of emotional process during competition: Nature, frequency, direction, duration and co-occurrence of discrete emotions. Psychology of Sport and Exercise, 13, 142-151.

Missildine, W. H. (1963). Your inner child of the past. New York, NY: Simon and Schuster.

Parker, W. D., \& Adkins, K. K. (1995). A psychometric examination of the multidimensional perfectionism scale. Journal of Psychopathology and Behavioral Assessment, 17, 323-334.

Parker, W. D., \& Stumpf, H. (1995). An examination of the multidimensional perfectionism scale with a sample of academically talented children. Journal of Psychoeducational Assessment, 13, 372-383.

Purdon, C., Antony, M. M., \& Swinson, R. P. (1999). Psychometric properties of the frost multidimensional perfectionism scale in a clinical anxiety disorder sample. Journal of Clinical Psychology, 55(10), 1271-1286.

Rhéaume, J., Freeston, M., Dugas, M., Letarte, H., \& Ladouceur, R. (1995). Perfectionism, responsibility and obsessive-compulsive symptoms. Behaviour Research and Therapy, 33(7), 785-794.

Sagar, S. S., \& Stoeber, J. (2009). Perfectionism, fear of failure and affective responses to success and failure: The central role of fear of experiencing shame and embarrassment. Journal of Sport and Exercise Psychological, 31, 602-627.

Schumaker, R. E., \& Lomax, R. G. (1996). A beginner's guide to sem. New Jersey: Mahwah.

Schumaker, R. E., \& Lomax, R. G. (2004). A beginner's guide to structural equation modeling. Mahwah, NJ: Psychology Press.

Serpa, S., Alves, P., \& Barreiros, A. (2004). Versão portuguesa da multidimensional perfectionism scale (mpsp): processos de tradução, adaptação e confiabilidade. Laboratório de Psicologia do Desporto: Universidade Técnica de Lisboa.

Shafran, R., Cooper, Z., \& Fairburn, C. G. (2002). Clinical perfectionism: a cognitive-behavioural analysis. Behaviour Research and Therapy, 40, 773-791.

Smith, R. E., Smoll, F. L., Cumming, S. P., \& Grossbard, J. R. (2006). Measurement of multidimensional sport performance anxiety in children and adults: The sport anxiety scale-2. Journal of Sport and Exercise Psychology, 28, 479-501.

Soares, M. J., Gomes, A. A., Macedo, A. F., \& Azevedo, M. H. P. (2003). Escala multidimensional de perfec- cionismo: adaptação à população portuguesa. Revista Portuguesa de Psicossomática, 5(1), 46-55.

Stumpf, H., \& Parker, W. D. (2000). A hierarquical structural analysis of perfectionism and its relation to other personality characteristics. Personal Individual Differences, 28, 837-852.

West, S. G., Finch, J. F., \& Curran, P. J. (1995). Structural equation models with nonnormal variables. problems and remedies. In I. R. Hoyle (Ed.), Structural equation modeling: Concepts, issues and applications (p. 56-75). Newbury Park, CA: Sage. 